\title{
Using SA508/533 for the HTGR Vessel Material
}

\author{
June 2012
}

The INL is a

U.S. Department of Energy

National Laboratory

operated by

Battelle Energy Alliance

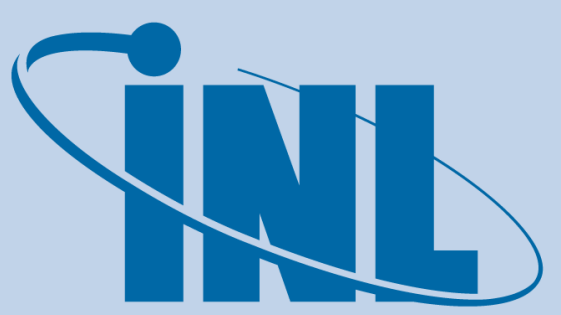

Idaho National Laboratory 


\section{DISCLAIMER}

This information was prepared as an account of work sponsored by an agency of the U.S. Government. Neither the U.S. Government nor any agency thereof, nor any of their employees, makes any warranty, expressed or implied, or assumes any legal liability or responsibility for the accuracy, completeness, or usefulness, of any information, apparatus, product, or process disclosed, or represents that its use would not infringe privately owned rights. References herein to any specific commercial product, process, or service by trade name, trade mark, manufacturer, or otherwise, does not necessarily constitute or imply its endorsement, recommendation, or favoring by the U.S. Government or any agency thereof. The views and opinions of authors expressed herein do not necessarily state or reflect those of the U.S. Government or any agency thereof. 


\title{
Using SA508/533 for the HTGR Vessel Material
}

June 2012

\author{
Idaho National Laboratory \\ VHTR Program \\ Idaho Falls, Idaho 83415
}

http://www.inl.gov

Prepared for the

U.S. Department of Energy

Office of Nuclear Energy

Under DOE Idaho Operations Office

Contract DE-AC07-05ID14517 



\section{VHTR Program}

\section{Using SA508/533 for the HTGR Vessel Material}

INL/EXT-12-25206

June 2012

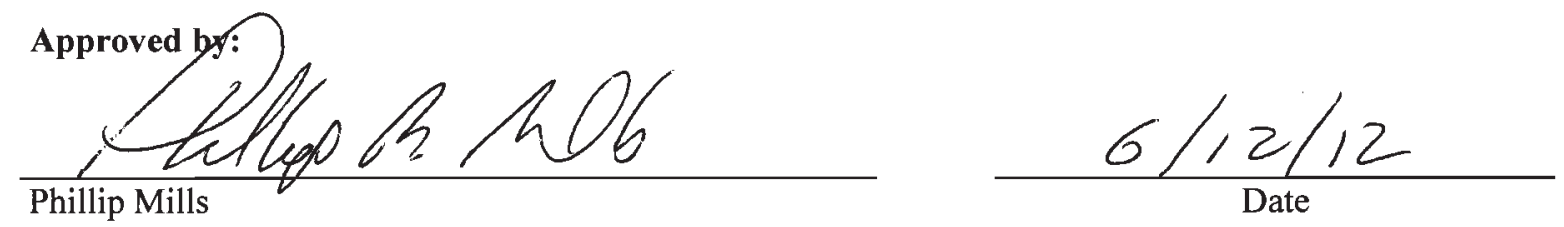

Engineering Director (acting) 



\begin{abstract}
This paper examines the influence of high temperature gas-cooled reactor module power rating and normal operating temperatures on the viability of using SA508/533 material for the high temperature gas-cooled reactor vessel system with emphasis on the calculated times at elevated temperatures approaching or exceeding American Society of Mechanical Engineers Boiler and Pressure Vessel Code, Section III Service Limits (Levels A, B, and C) to which the reactor pressure vessel could be exposed during normal operation and postulated pressurized and depressurized conduction cooldown events over its design lifetime.
\end{abstract}




\section{PREFACE}

This report examines a conclusion reached by some General Atomics analysis personnel in 1992 during early design work on their Modular High Temperature Gas Reactor. The conclusion was that there is an upper limit in the range of 450 to $500 \mathrm{MW}(\mathrm{t})$ on the rating of a prismatic high temperature gascooled reactor (HTGR) core above which SA508/533 material cannot be used for the reactor pressure vessel (RPV). This conclusion was based on analyses that showed the higher the rating of the HTGR core, the higher the peak temperatures reached in the fuel and RPV during conduction cooldown events. The HTGR module design currently being considered for a commercial next generation nuclear plant application uses a prismatic reactor concept with a peak rating of $625 \mathrm{MW}(\mathrm{t})$. The SA508/533 material is being targeted for use in the RPV in this design. Accordingly, this report examines information currently available on the temperature response of the RPV during conduction cooldown events to reevaluate the earlier General Atomics conclusion and determine if this rating precludes the use of this material for that RPV. This report also examines the influence of the reactor inlet temperature during normal operation on the viability of using this material.

Other factors that affect the viability of using SA508/533 material for the RPV in this application include:

- Meeting the current negligible creep criterion at normal RPV operating temperatures

- The duty cycle of the plant, which includes other events that affect RPV temperature such as the loss of feedwater

- Potential increased temperature effects from air and/or water ingress during accident transients

- Successful completion of analyses to confirm compliance with Section III, Division 5 requirements of the American Society of Mechanical Engineers Boiler and Pressure Vessel Code over the 60-year design life of the vessel, including evaluation of time dependent primary stresses, strain limits, and creep-fatigue damage for all transients.

It is not the objective of this report to address all of these factors; but to address the question of whether the time at temperature response of the RPV during normal operation and conduction cooldown events is a limiting factor on the core rating of an HTGR module for which SA508/533 material can be used as the vessel material. 


\section{EXECUTIVE SUMMARY}

One objective of the Next Generation Nuclear Plant (NGNP) Project in deploying the initial high temperature gas-cooled reactor (HTGR) technology in industrial applications is to use, where possible, traditional light water reactor material SA508/533 for the primary helium vessel system. The basis for this objective is the wide range of experience with this material in the current light water reactor fleet, the ready availability of the material, and its lower cost when compared with alternative materials such as 2-1/4 Cr-1Mo-1V and 9Cr-1Mo-V. Other concerns with these alternative materials include the status of ASME Code acceptance for this service and the fabricability of $9 \mathrm{Cr}-1 \mathrm{Mo}-\mathrm{V}$. This report evaluates one factor that affects the viability of using SA508/533 in this service - the times at temperature of the vessels during normal operation and limiting plant events. Of the three vessels that make up the vessel system [reactor pressure vessel (RPV), cross-vessel, and the heat transport system vessel ${ }^{\mathrm{a}}$ ], the RPV is the most limiting. All three vessels are exposed to the same reactor inlet temperatures (RITs) during normal operation, but the RPV will see much higher temperatures during some plant events, particularly loss of forced cooling conduction cooldown events. Both normal operation and conduction cooldown events must be evaluated to determine whether SA508/533 is an acceptable material for the RPV.

The temperature responses of the RPV during conduction cooldown events were examined because of a conclusion reached by some General Atomics personnel performing analyses during early design work in 1992 on the modular high temperature gas reactor (MHTGR), indicating that the higher the rating of the HTGR core, the higher the peak temperatures in the fuel and the RPV reached during these events. Plant ratings up to $500 \mathrm{MW}(\mathrm{t})$ were examined, at which point the peak temperatures in the RPV exceeded the limit for SA508/533 material at that time. It was then estimated that a core rating somewhere in the range of 450 to $500 \mathrm{MW}(\mathrm{t})$ would be the upper limit on core rating for use of SA508/533 material for the RPV. At about the same time or shortly thereafter, the American Society of Mechanical Engineers (ASME) Code Case N-499 was first approved for SA508/533 material. This code case permits a limited number of excursions in temperatures above $700^{\circ} \mathrm{F} / 370^{\circ} \mathrm{C}$ to a maximum of $1000^{\circ} \mathrm{F} / 540^{\circ} \mathrm{C}$ for limited periods of time under Level A, B, C, and D Service Limits; temperatures in excess of the Level A Service Limit temperature of $700^{\circ} \mathrm{F} / 370^{\circ} \mathrm{C}$ are permitted for up to 3,000 hours and temperatures in excess of the Level B Service Limit temperature of $800^{\circ} \mathrm{F} / 425^{\circ} \mathrm{C}$ up to $1000^{\circ} \mathrm{F} / 540^{\circ} \mathrm{C}$ are permitted for up to 1,000 hours. The number of anticipated operating conditions where metal temperatures exceed $800^{\circ} \mathrm{F} / 425^{\circ} \mathrm{C}$ shall be limited to a total of three events. Since conduction cooldown transients are considered infrequent events, the Level C Service Limits apply, permitting temperature excursions above $800^{\circ} \mathrm{F} / 425^{\circ} \mathrm{C}$ but below $1000^{\circ} \mathrm{F} / 540^{\circ} \mathrm{C}$. (In November 2011 this Code Case was incorporated into Division 5 of Section III of the ASME Code.) Accordingly, the impact of temperature transients during conduction cooldown events on the viability of using SA508/533 material for the HTGR RPV depends on both the peak temperatures reached and the durations of the high temperatures during the event.

Several analyses performed subsequent to General Atomics design work on the MHTGR have investigated the factors affecting the ability to use SA508/533 material for the RPV. These include finalizing the design of the MHTGR, General Atomic's development of the gas turbine modular helium reactor (GTMHR) in the 1990s, AREVA's development of the Very High Temperature Reactor (VHTR), the NGNP Project's preconceptual design work on the NGNP in 2007 with subsequent trade studies in 2008, and the Korean Atomic Energy Research Institute's (KAERI) development of a VHTR that has a core patterned after the GTMHR.

a The heat transport system of an HTGR nuclear heat supply system can take several forms, including a steam generator, intermediate heat exchanger, or direct Brayton cycle turbine generator with heat recovery heat exchanger. The heat transport system vessel forms one part of the helium pressure boundary for this system; the other part are the tubes of the steam generator, intermediate heat exchanger or the heat recovery heat exchanger. 
This report summarizes the results of these investigations to determine if SA508/533 material can be used for HTGR designs that fall within the range of parameters recommended by the NGNP Project for initial deployment of HTGR technology in industrial applications. These parameters include a reactor outlet temperature (ROT) in the range of 725 to $850^{\circ} \mathrm{C}$ and a reactor rating between 200 and $625 \mathrm{MW}(\mathrm{t})$.

Based on reviews of these investigations, which focused on normal operating conditions and the temperature transients during conduction cooldown events, the following conclusions have been drawn:

- SA 508/533 material can be used for the HTGR vessel system in the range of ROTs and reactor ratings recommended by the NGNP Project. There is no data currently available on the peak temperatures reached during conduction cooldown events for the $625 \mathrm{MW}(\mathrm{t})$ prismatic reactor design. Data is available for similar designs with core ratings of $600 \mathrm{MW}(\mathrm{t})$. It is judged, based on review of the trends in peak temperature versus core rating, that SA508/533 material will be acceptable for use for the $625 \mathrm{MW}(\mathrm{t})$ core rating for ROTs up to $770^{\circ} \mathrm{C}$. For ROTs above $770^{\circ} \mathrm{C}$, the inlet temperatures under normal operating conditions may exceed the unrestricted operating limits of SA508/533, but changes in either RPV material or reactor inlet flow configuration will be required.

- SA508/533 material is recommended for normal operations as follows:

- Its use is unrestricted for RITs $\leq 370^{\circ} \mathrm{C}$ as long as the current negligible creep criterion is met. Based on prior design data for prismatic cores, this would correspond to a maximum ROT of $\sim 770^{\circ} \mathrm{C}$. The recent recommendations by General Atomics and AREVA for the initial deployment of the HTGR technology employ ROTs below this value $\left(725\right.$ to $\left.750^{\circ} \mathrm{C}\right)$, providing confidence that the RITs should not be factors in use of the SA508/533 material for the vessel system for these designs.

- It can be used at ROTs $>770^{\circ} \mathrm{C}$ but $\leq 850^{\circ} \mathrm{C}$ by redirecting the reactor inlet flow inside the core barrel through either riser tubes or axial holes in the permanent side reflector, again accounting for the negligible creep criterion. ${ }^{\mathrm{b}}$ A maximum RIT of $450^{\circ} \mathrm{C}$ and a configuration similar to the GTMHR has been found to produce acceptable results under normal operating conditions for these configurations.

- It can be used at ROTs $>850^{\circ} \mathrm{C}$ but $\leq 950^{\circ} \mathrm{C}$ by redirecting the reactor inlet flow inside the core barrel either through riser tubes or holes in the permanent side reflector and adding a vessel cooling system flow of low temperature helium through the annulus between the core barrel and the RPV; again accounting for the negligible creep criterion. Note that the vessel cooling system would not be credited in calculations of the expected RPV temperature response during infrequent and limiting events that increase the RPV temperature.

- An alternative that needs further investigation for RITs $>370^{\circ} \mathrm{C}$ is the addition of insulation to the inner wall of the RPV. There are concerns, however, with increased fuel temperatures during conduction cooldown events, problems with attaching the insulation, effects on vessel inservice inspection (ISI) and the consequences of loose insulation during transients that would need to be addressed if this alternative were being considered during the design process.

Adding insulation to the inner walls of the cross-vessel and heat transport system vessel will be needed to maintain these vessels within the unrestricted temperature range for RITs $>370{ }^{\circ} \mathrm{C}$. The temperatures of these vessels are not affected by conduction cooldown transients. This is typically encapsulated solid insulation that will not be of concern during transients, (e.g., coming loose and clogging flow passages).

b AREVA has raised concerns with redirecting the reactor inlet flow through the reflector because of the effects of loss of graphite in this area on heat transfer, moderation, and vessel fluence, stating that the analyses of this configuration may not have adequately addressed these areas in the calculations. These concerns would have to be addressed if these configurations were being considered in future design work with RITs $>370^{\circ} \mathrm{C}$. 
- SA508/533 material is recommended for Conduction Cooldown Events as follows:

- The depressurized conduction cooldown event is more limiting than the pressurized conduction cooldown event on peak RPV temperatures reached during the event and the duration of temperatures in excess of the Level A and, in some cases, Level B Service Limit temperatures. ${ }^{c}$ This conclusion addresses only the peak temperatures reached during the transients, it does not consider the stress levels at the peak temperatures. These stresses would be higher for the pressurized condition but at lower temperature. Whether the depressurized or pressurized condition is more limiting considering stress at temperature will be determined during the design process. This does not necessarily affect the selection of the material but rather the dimensions of the vessels required to ensure that the calculated stresses are within acceptable values.

- In all cases reviewed for core ratings in the range of 350 to $600 \mathrm{MW}(\mathrm{t})$ and ROTs from 687 to $950^{\circ} \mathrm{C}$, the Level A Service Limit temperature $\left(700^{\circ} \mathrm{F} / 370^{\circ} \mathrm{C}\right)$ was exceeded during pressurized and depressurized conduction cooldown events. The Level B Service Limit was exceeded (1) in the final design for the MHTGR $350 \mathrm{MW}(\mathrm{t})$ core, (2) for cases where higher power densities were employed in smaller cores (e.g., increasing the MHTGR core rating from 350 to $410 \mathrm{MW}(\mathrm{t})$ in the early General Atomics design evaluations), and (3) for core ratings at or above 450 to $500 \mathrm{MW}(\mathrm{t})$, depending on the specific core configuration.

- The Level C Service Limit temperature $\left(1000^{\circ} \mathrm{F} / 540^{\circ} \mathrm{C}\right)$ was never exceeded. In no case was the 1,000 hour limit for temperatures in excess of $800^{\circ} \mathrm{F} / 425^{\circ} \mathrm{C}$ and the 3,000 hour limit for temperatures in excess of $700^{\circ} \mathrm{F} / 370^{\circ} \mathrm{C}$ approached in a single event.

- There are many design and performance characteristics that affect the peak temperature that the RPV will experience during conduction cooldown events. These include core configuration ${ }^{\mathrm{d}}$ (e.g., number of fuel columns, number of fuel layers, diameter of the core and RPV) and fuel element power density.

- When the core configuration is constant (the number of fuel columns and layers and the RPV diameter are the same), the peak temperatures reached in conduction cooldown events will be a direct function of the core rating.

- For cores with the same core rating and the same number of fuel columns but a lower number of fuel layers as other cores (i.e., the shorter core has a higher power density), the peak RPV temperature during conduction cooldown events increases because the shorter core reduces the area for radial heat transport during the event. This is not the case for cores with the same number of fuel layers but different numbers of fuel columns and higher power density to achieve the same core rating. The peak temperatures reached during these events are essentially the same.

- If the plants with core ratings in the range 500 to $600 \mathrm{MW}(\mathrm{t})$ have three of the depressurized or pressurized conduction cooldown transients, further operation of the RPV would not be permitted because of the Code limit of three excursions above the Level B Service Limit $\left(800^{\circ} \mathrm{F} / 425^{\circ} \mathrm{C}\right)$, which impacts the structure of the duty cycle assumed for these modules and the investment risk of the plant.

c All of the depressurized conduction cooldown events reviewed assumed a rapid depressurization of the primary helium system. Although it appears obvious, it has not been confirmed in this review that the rapid depressurization produces higher temperatures than if the depressurization were more prolonged (e.g., if it were coincident with an instrument line break and no operator action were taken to depressurize the system). Such confirmation will be needed in future design work.

d The fueled section of the core is made up of prismatic graphite fueled blocks stacked in an annular configuration arranged vertically in layers and radially in columns. Different core designs can incorporate different numbers of fuel layers and fuel columns. The power density of the fuel within the fueled blocks can also be varied. The fuel volume is a product of the number of layers, the number of columns; the power rating of the core is the product of the fuel volume and power density. 
- The analyses reviewed herein covered several different configurations of the reactor inlet flow path from the cross-vessel to the upper plenum, including flow through channels in the annulus between the core barrel and the RPV and through the reflector inside the core barrel. These variations in configuration did not appear to have a material effect on the peak temperatures reached during the events nor the duration of temperatures that exceed the Level A and B Service Limit temperatures. This will need to be confirmed during the HTGR plant design.

- Analyses for a $600 \mathrm{MW}(\mathrm{t})$ core show that changes in the ROTs from 750 to $950^{\circ} \mathrm{C}$ with corresponding changes in RIT have a relatively small effect $\left(\sim 30^{\circ} \mathrm{C}\right)$ on the RPV peak temperatures reached in these events.

Future design work for the initial deployment of the HTGR technology in industrial applications shall include analyses that address each of these areas and assess the validity of these conclusions on the viability of using SA508/533 for the vessel system. 


\section{CONTENTS}

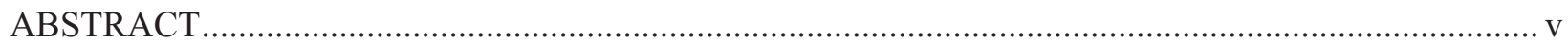

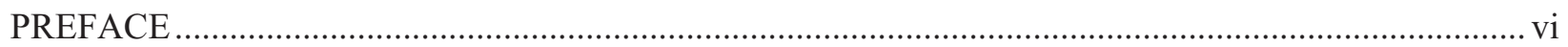

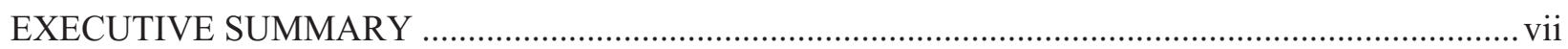

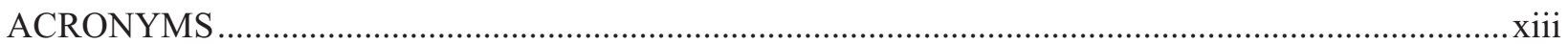

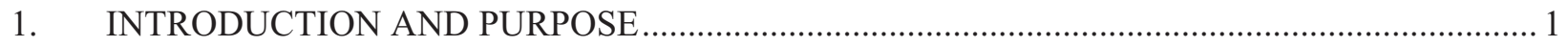

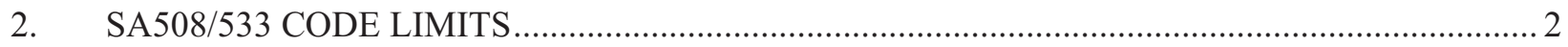

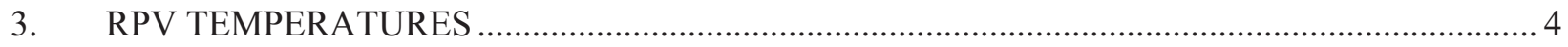

3.1 Normal Operating Temperatures.................................................................................. 5

3.2 Temperatures During Conduction Cooldown Events ...................................................... 11

3.2.1 Peak RPV Temperatures Reached in DCC \& PCC Events........................................ 12

3.2.2 Time at Temperature During DCC and PCC Events .............................................. 15

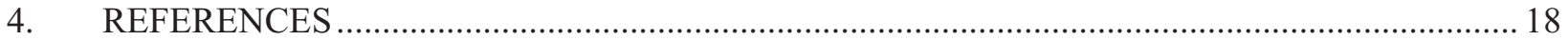

\section{FIGURES}

Figure 1. Typical nuclear heat supply system vessel system................................................................ 1

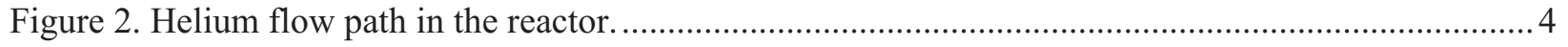

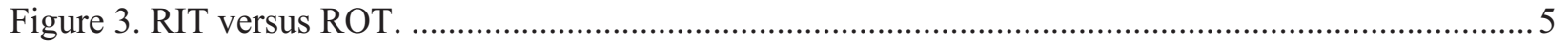

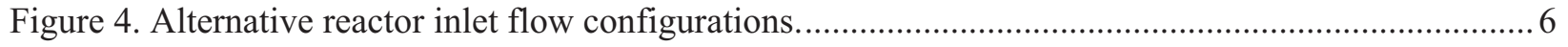

Figure 5. Configuration of the cooled-vessel design concept. ............................................................... 7

Figure 6. Peak RPV Temperature During a DCC Event as a Function of Core Rating............................ 13

Figure 7. Peak RPV Temperature During a DCC Event as a Core Power Density................................. 13

Figure 8. Influence of inlet/outlet temperature on maximum RPV temperature during a DCC

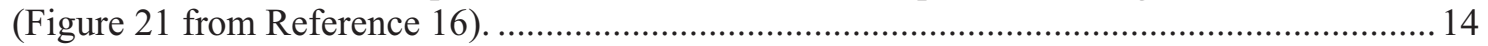

Figure 9. RPV Temperature Response During DCC, 350 MW(t) MHTGR.......................................... 16

Figure 10. RPV temperature response to PCC event, 600 MW(t) GT-MHR. ........................................ 16

Figure 11. RPV temperature response to DCC event, $600 \mathrm{MW(t)}$ GT-MHR......................................... 16

\section{TABLES}

Table 1. Operating parameters that affect major HTGR components.................................................... 1

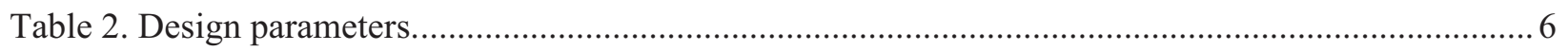

Table 3. Results of INL Analyses of RPV Temperature versus Reactor Inlet and Outlet 


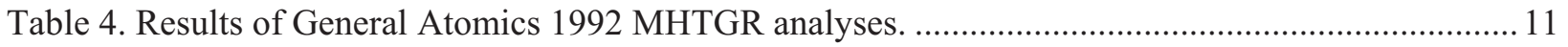

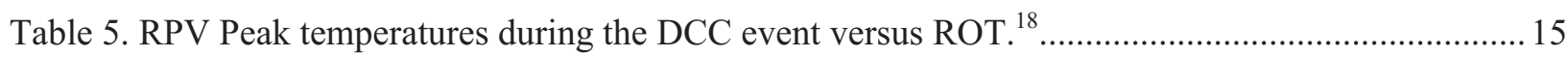




\section{ACRONYMS}

ASME American Society of Mechanical Engineers

BPV Boiler and Pressure Vessel

DCC depressurized conduction cooldown

GTMHR gas turbine modular helium reactor

HTGR high temperature gas-cooled reactor

INL Idaho National Laboratory

ISI inservice inspection

KAERI Korean Atomic Energy Research Institute

MHTGR Modular High Temperature Gas Reactor

NGNP Next Generation Nuclear Plant

PSR permanent side reflector

RCCS reactor cavity cooling system

RIT reactor inlet temperature

ROT reactor outlet temperature

RPV reactor pressure vessel

VCS vessel cooling system

VHTR very high temperature reactor 


\section{Using SA508/533 for the HTGR Vessel Material}

\section{INTRODUCTION AND PURPOSE}

The high temperature gas-cooled reactor (HTGR) vessel system is comprised of a reactor pressure vessel (RPV), cross vessel, and heat transport system vessel (steam generator vessel) as shown in Figure 1. The material selected for this vessel system depends on several factors, two of the more significant being vessel temperatures during normal operation and peak temperatures to which the vessels could be exposed during postulated events that potentially subject the vessels to Level B, C, or D Service Limits of the American Society of Mechanical Engineers (ASME) Boiler and Pressure Vessel (BPV) Code. This paper discusses the effect of selected design characteristics of an HTGR plant on these temperatures and the ability to use traditional light water reactor pressure vessel material, SA508/533, for the HTGR vessel. The conditions for the HTGR RPV will thus be the focus of this paper. The impact on the cross vessel and heat transport system vessel designs are discussed

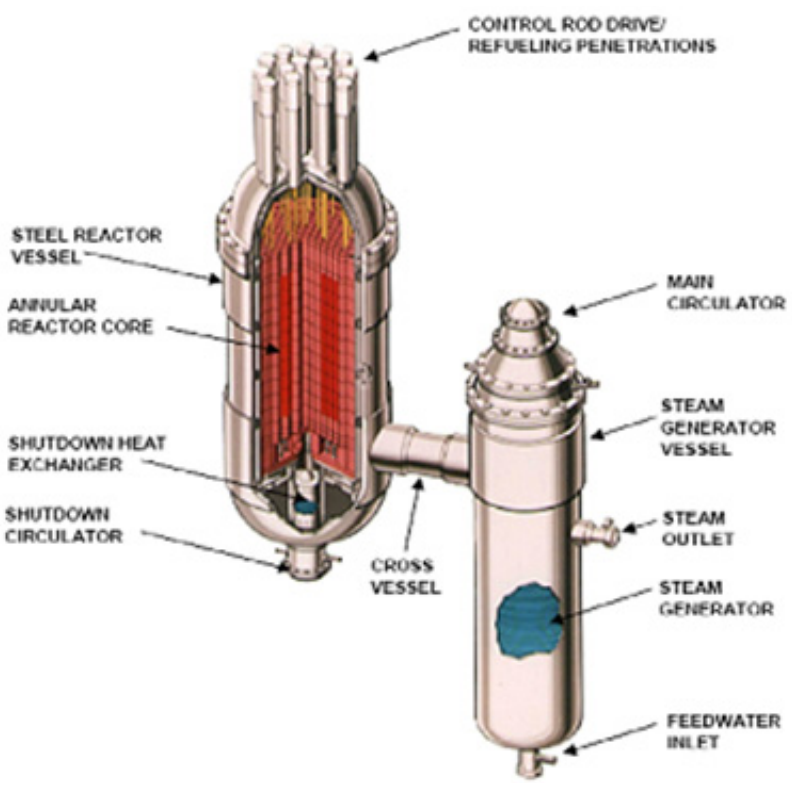

Figure 1. Typical nuclear heat supply system vessel system. where appropriate.

Table 1 summarizes the design parameters that have the greatest effect on the vessel system design and material. ${ }^{1}$ This paper focuses on three of these: core inlet temperature, core outlet temperature, and core power level (also referred to herein as core rating). The primary coolant pressure affects the required dimensions of the vessel (wall thickness, flange dimensions, etc.) considering the structural capacities of the material at the design temperatures - as the design temperatures increase, the structural capacities of the materials decrease. For those materials with lower structural capacities at higher temperatures, the required dimensions (resulting in thicker and heavier vessels) may become impractical from a manufacturing and economic perspective. These considerations generally apply once a specific range of material is identified as applicable for the temperature conditions to which the material will be exposed over its lifetime. Since this paper discusses the temperature effect, the impact of operating pressure on the final selection of the vessel material is not discussed further.

Table 1. Operating parameters that affect major HTGR components.

\begin{tabular}{|l|c|c|c|c|}
\hline & $\begin{array}{c}\text { Core Inlet } \\
\text { Temperature }\end{array}$ & $\begin{array}{c}\text { Core Outlet } \\
\text { Temperature }\end{array}$ & Core Power Level & $\begin{array}{c}\text { Primary Coolant } \\
\text { Pressure }\end{array}$ \\
\hline Vessel System & $\mathrm{X}$ & & $\mathrm{X}$ & $\mathrm{X}$ \\
\hline Primary Circulator & $\mathrm{X}$ & & & $\mathrm{X}$ \\
\hline Secondary Circulator & $\mathrm{X}$ & & $\mathrm{X}$ & \\
\hline Tubular IHX & & $\mathrm{X}$ & $\mathrm{X}$ & \\
\hline Compact IHX & & $\mathrm{X}$ & & \\
\hline
\end{tabular}


The Next Generation Nuclear Plant (NGNP) Project developed high level functional and performance requirements to support the design and initial deployment of HTGR plants in commercial operation. ${ }^{2}$ These requirements result from extensive review of potential end user energy needs and recommendations from a Senior Advisory Group comprised of representatives from the suppliers of the HTGR technology. These requirements also are the bases for recent industry planning for commercializing this technology. The requirements pertinent to this paper are as follows:

- The reactor outlet temperature (ROT) will be in the range of 725 to $850^{\circ} \mathrm{C}$

- The reactor rating will be between 200 and $625 \mathrm{MW}(\mathrm{t})$

- $\quad$ The material for the vessel system will be SA508/533.

Over the longer term, the NGNP Project has identified applications requiring higher operating temperatures up to $950^{\circ} \mathrm{C}$. As shown herein, this higher outlet temperature can put additional constraints on the RPV system design, resulting in the consideration of vessel materials other than SA508/533. Thus, this paper focuses on the factors that affect using SA508/533 as the vessel material for the full range of conditions recommended by the NGNP Project for the initial deployment of the HTGR technology.

\section{SA508/533 CODE LIMITS}

The 2011 Addenda to the 2010 Edition of the ASME BPV Code, Section III, Division $5^{3}$ includes temperature limits on SA508/533 material during normal operation and abnormal events. These are specified in Subsection HB, Subpart B, Appendix I, Article HBB-I-3000, Design:

The rules for design are presented in (a) through (i). Refer to Figs. HBBI-3000-1 through HBB-I-3000-14 and Tables HBB-I-3000-1 through HBB-I-3000-8.

(a) The design rules of Division 1, Article NB-3000 shall be satisfied for all Design, Service, and Test Loadings for which metal temperatures do not exceed $700^{\circ} \mathrm{F}\left(370^{\circ} \mathrm{C}\right)$. The design conditions shall be as defined in Division 1, Article NB-3000.

(b) Metal temperatures exceeding $700^{\circ} \mathrm{F}\left(370^{\circ} \mathrm{C}\right)$ are permitted only for loading associated with Levels $B, C$, and D Service Limits. The applicable rules of Division 1, Article NH-3000 shall be satisfied for these conditions.

(c) Metal temperatures shall not exceed $800^{\circ} \mathrm{F}\left(425^{\circ} \mathrm{C}\right)$ for loadings associated with Level B Service Limits. Metal temperatures shall not exceed $1,000^{\circ} \mathrm{F}\left(540^{\circ} \mathrm{C}\right)$ for loadings associated with Level C or Level D Service Limits.

(d) The component design shall be based on a maximum cumulative time of $3,000 \mathrm{hr}$ at metal temperatures in the range of $700^{\circ} \mathrm{F}\left(370^{\circ} \mathrm{C}\right)$ to $800^{\circ} \mathrm{F}\left(425^{\circ} \mathrm{C}\right)$ and $1,000 \mathrm{hr}$ at metal temperatures exceeding $800^{\circ} \mathrm{F}$ $\left(425^{\circ} \mathrm{C}\right)$ up to $1,000^{\circ} \mathrm{F}\left(540^{\circ} \mathrm{C}\right)$

(e) The number of anticipated operating conditions where metal temperatures exceed $800^{\circ} \mathrm{F}\left(425^{\circ} \mathrm{C}\right)$ shall be limited to total of 3 .

Items $(f)$ through $(i)$ are not shown for simplicity since they do not address temperature level requirements of interest herein. 
Level A, B, C, and D Service Limits are defined in Subsection NCA-2142.4(b) ${ }^{4}$ :

Service Limits. The Design Specification may designate Service Limits as defined in (1) through (4) below.

(1) Level A Service Limits. Level A Service Limits are those sets of limits that must be satisfied for all Level A Service Loadings identified in the Design Specifications to which the component or support may be subjected in the performance of its specified service function.

(2) Level B Service Limits. Level B Service Limits are those sets of limits that must be satisfied for all Level B Service Loadings identified in the Design Specifications for which these Service Limits are designated. The component or support must withstand these loadings without damage requiring repair.

(3) Level C Service Limits. Level C Service Limits are those sets of limits that must be satisfied for all Level C Service Loadings identified in the Design Specifications for which these Service Limits are designated. These sets of limits permit large deformations in areas of structural discontinuity that may necessitate the removal of the component or support from service for inspection or repair of damage to the component or support. Therefore, the selection of this limit shall be reviewed by the Owner for compatibility with established system safety criteria (NCA-2141).

(4) Level D Service Limits. Level D Service Limits are those sets of limits that must be satisfied for all Level D Service Loadings identified in the Design Specifications for which these Service Limits are designated. These sets of limits permit gross general deformations with some consequent loss of dimensional stability and damage requiring repair, that may require removal of the component or support from service. Therefore, the selection of this limit shall be reviewed by the Owner for compatibility with established system safety criteria (NCA-2141).

For this report, normal operation loadings will be subject to Level A Service Limits and the postulated emergency condition loadings that have the most potential for limiting the use of SA508/533 material in the vessel system application will be subject to Level C Service Limits, since they are expected to be infrequent events but not limiting faults from a safety perspective.

It should be noted that these limits apply to the maximum local average wall temperature of the vessel in accordance with Subsection NH, Article NH-3000

NH-3112.2 Specified Temperature. The specified temperature history for the loading category shall enable the designer to describe a temperature value not less than the maximum local wall averaged temperature that will exist in the structural metal in a given zone of the component. And for the particular analyses of Service Loadings (NH-3113.2), the designer shall determine the history of the maximum local metal temperature in a given zone and shall use these metal temperature histories in the computations to show compliance with the limits of $\mathrm{NH}-3200$.

For the purposes of the following discussions, where appropriate, it is assumed that the calculated midwall temperature is representative of the averaged vessel wall temperature and is assumed to be adequate to compare to the temperature limits established in Subsection HB, Subpart B, Appendix I. 
Evaluations supported by General Atomics indicate that the present ASME Code limits may be conservative. ${ }^{6}$ These evaluations show that SA508/533 could support a 60-year plant design life at temperatures in the range of $400^{\circ} \mathrm{C}$. If necessary, a new code case could be formulated using this data to increase the temperature capabilities and to potentially modify the limit of three events exceeding the Level B Service Limits.

\section{RPV TEMPERATURES}

The RPV temperatures of interest in establishing the viability of using SA508/533 material are the peak temperatures that will be reached during normal operation and during the most limiting postulated events affecting RPV temperature. The HTGR helium flow path during normal operation includes down-flow through the core from the upper plenum to the lower plenum where the highest temperatures in the reactor, the ROTs, are sustained as shown in Figure 2. The reactor outlet flows through the inner duct of the cross vessel into the high temperature inlet of the heat transport system (either a steam generator, intermediate heat exchanger, or Brayton cycle turbine generator). The helium exits from the heat transport system along the heat transport system vessel walls through the outer annulus of the cross vessel and into the reactor as shown in Figures 1 and 2. The temperature at this point is referred to as the reactor inlet temperature (RIT). The helium flows upward from the cross-vessel to the upper plenum in channels positioned within the annulus between the core barrel and the RPV inner wall as shown in Figure 2, or in holes or risers inside the core barrel through the permanent side reflector, depending on the specific reactor design. In any configuration, the RPV temperature during normal operation is influenced by the RIT. The configuration of the return flow affects the degree to

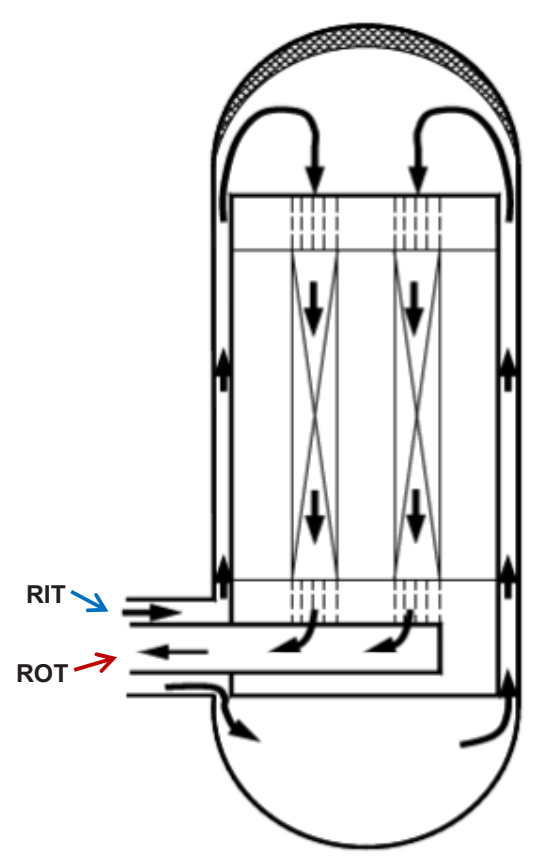

Figure 2. Helium flow path in the reactor. which it is influenced as discussed below.

Based on the analyses at the time of this writing, the more limiting events affecting RPV temperature are the loss of forced cooling conduction cooldown events. The temperatures reached in the depressurized conduction cooldown (DCC) event are generally higher, although the temperatures reached in either event may exceed Code limits on the frequency that higher temperatures can be exceeded and still continue to operate the vessel. The stress levels for the pressurized event will also be higher than for the depressurized events but the peak temperature will be lower. Detailed design analyses will be required to determine which condition is the more limiting. Accordingly, both events must be considered in evaluating the viability of SA508/533 for this service.

In both events, all forced cooling is lost. In the depressurized event, the reactor is depressurized by a loss of helium through a breach in the primary coolant system boundary. In both events, decay heat in the core is dissipated via primarily radial heat transport through the graphite reflector, the core barrel and the RPV to the reactor cavity cooling system. The peak temperatures reached in the RPV and the periods over which these temperatures persist are a function of several variables as discussed in Section 3.2.

The next section discusses the impact of normal operating temperature and reactor inlet flow configuration on the ability to use SA508/533 material for the RPV. 


\subsection{Normal Operating Temperatures}

As noted previously, SA508/533 has an unrestricted operating temperature limit of $370^{\circ} \mathrm{C}$ (Level A Service Limit), subject to meeting the current negligible creep criterion at the operating temperature. Under normal operating conditions, the RPV temperature is a strong function of the RIT. In turn, the RIT is a strong function of the ROT. Figure 3 shows relationships of RIT to ROT for known designs. Data points (triangles) are shown for prismatic core designs developed by AREVA and General Atomics and

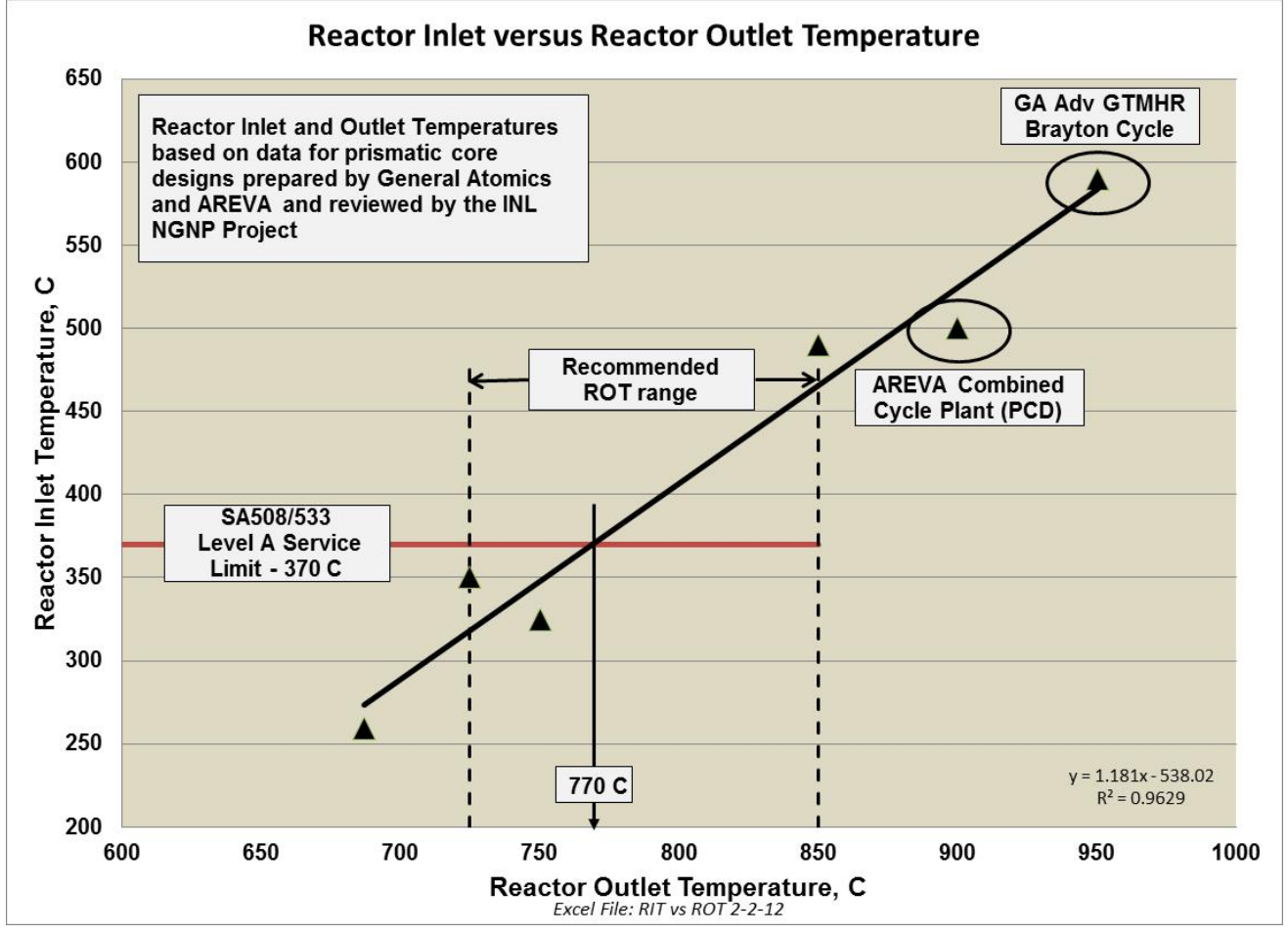

Figure 3. RIT versus ROT.

reviewed by the NGNP Project. A linear fit of this data was used to generate the solid line. The Level A Service Limit temperature of $370^{\circ} \mathrm{C}$ is also shown. It intersects with the linear representation of RIT versus ROT at an ROT of $770^{\circ} \mathrm{C}$, an ROT a little less than halfway through the 725 to $850^{\circ} \mathrm{C}$ range of ROT recommended by the NGNP Project for the initial deployment of the HTGR technology. The two higher temperature ROTs are highlighted (circled) to indicate that they are outside the initial recommended range and conditions for Brayton cycle designs either in direct cycle [General Atomics, gas turbine modular helium reactor (GTMHR)] or indirect cycle (AREVA Antares) configurations for development in the second phase higher temperature deployment of the HTGR technology. The plant designs in the NGNP Project-recommended range of ROT are for steam, electricity, and hot gas generation to support near-term industrial applications such as co-generation, nonconventional oil recovery (e.g., bitumen from oil sands), and carbon conversion to transportation fuel and chemicals.

The intersection of the Level A Service Limit temperature with the linear relationship of RIT with ROT in Figure 3 is shown to illustrate the potential worst case effect of a specific reactor inlet helium temperature on the ability to use SA 508/533 material. The worst case would be if the inlet helium flows directly in the annulus between the outer wall of the core barrel and the inner wall of the RPV (see 
Figure 2). This would generate the highest RPV wall temperatures during normal operation. ${ }^{\mathrm{e}}$ However, the reactor inlet flow path for the General Atomics and AREVA designs is through azimuthally segmented up-riser channels in this annulus that provide an additional barrier between the inlet flow and the RPV inner wall.

In 2008, the NGNP Project tasked General Atomics, AREVA, and Westinghouse/PBMR Pty (Ltd) to perform several trade studies. These included assessing the material alternatives for the HTGR vessel systems. The study performed by General Atomics for the NGNP Project in 2008 included evaluations by the Korean Atomic Energy Research Institute (KAERI) of alternative inlet flow configurations to reduce RPV temperatures with high RITs. ${ }^{7}$ Figure 4 shows the three configurations evaluated along with the original configuration (Figure 2) designated as the reference case. ${ }^{\mathrm{f}}$ These evaluations were performed for the following plant design conditions:

Table 2. Design parameters.

\begin{tabular}{lc}
\hline Design Parameters & Values \\
\hline Core thermal power $(\mathrm{MWt})$ & 600 \\
Number of fuel columns & 102 \\
Number of fuel block layers & 10 \\
Thermal Power Density $\left(\mathrm{MW} / \mathrm{m}^{3}\right)$ & 6.6 \\
Effective inner diameter of active core $(\mathrm{m})$ & 2.95 \\
Effective outer diameter of active core $(\mathrm{m})$ & 4.83 \\
Height of active core $(\mathrm{m})$ & 7.93 \\
Height of top/bottom reflector & 1.59 \\
Outer diameter of side reflector & 6.85 \\
Number of riser holes & 54 \\
Diameter of riser hole $(\mathrm{m})$ & 0.2 \\
Diameter of riser hole position $(\mathrm{m})$ & 6.57 \\
Core inlet pressure $(\mathrm{Mpa})$ & 7.0 \\
Core inlet temperature $\left({ }^{\circ} \mathrm{C}\right)$ & 490 \\
Core outler temperature $\left({ }^{\circ} \mathrm{C}\right)$ & 950 \\
Coolant flow rate $(\mathrm{kg} / \mathrm{sec})$ & 250 \\
RPV material & $\mathrm{SA} 50 / 533 \mathrm{steel}$ \\
Outer diameter of RPV $(\mathrm{m})$ & 8.04 \\
Thickness of RPV $(\mathrm{m})$ & 0.19 \\
Width of RCCS channel $(\mathrm{m})$ & 0.0458 \\
Length of RCCS channel $(\mathrm{m})$ & 0.254 \\
Thickness of RCCS channel $(\mathrm{m})$ & 0.0048 \\
\hline
\end{tabular}
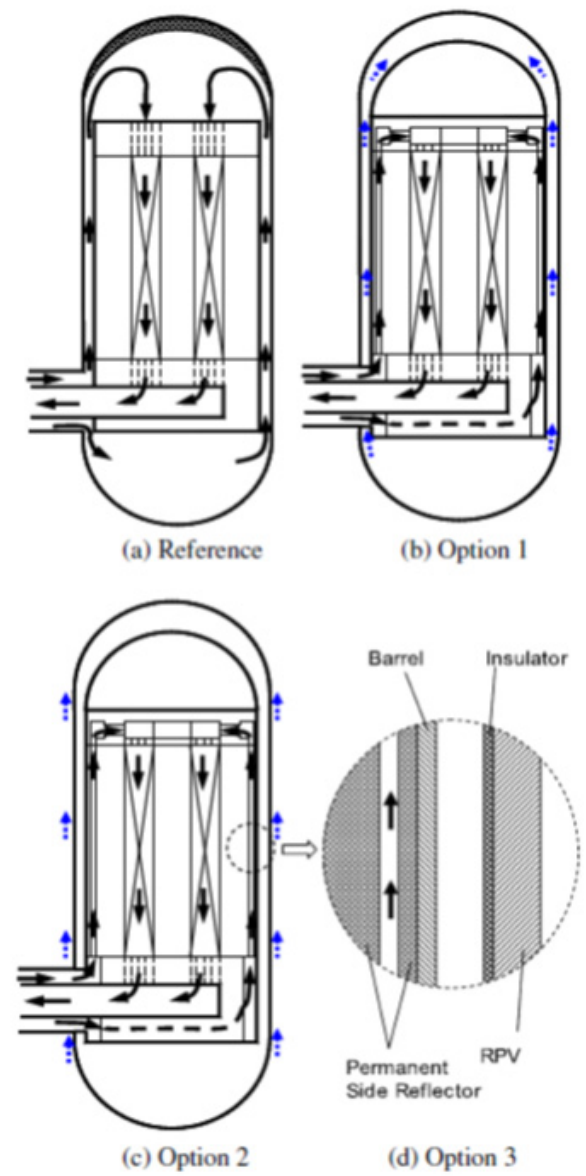

Figure 4. Alternative reactor inlet flow configurations.

The options evaluated included rerouting the inlet flow inside the core barrel through risers in the permanent side reflector with barriers installed to prevent reactor inlet flow through the annulus between the core barrel and the RPV. This arrangement has three variations that were evaluated. In the first, a vessel cooling system (VCS) is installed and low temperature helium $\left(140^{\circ} \mathrm{C}\right)$ is passed through the annulus between the core barrel and the RPV. In the second, the low temperature helium is blown over

e Figure 3 does not account for the difference in the RIT and the average wall temperature. Calculations show that this difference varies between $\sim 10$ and $\sim 25^{\circ} \mathrm{C}$, depending on the inlet temperature. It has not been considered in Figure 3 for conservatism but would be considered in the design process.

f KAERI included similar calculations in later design work on their HTGR design. These are covered in references 8 and 9. 
the outer wall of the RPV in the reactor cavity. In the third, the inner wall of the RPV is insulated. These evaluations drew the following conclusions:

- Depending on the analysis approach applied, no or very little cooling flow through the core barrel to RPV annulus is required to reduce the RPV temperature sufficiently to permit use of the SA 508/533 material.

- Directing the flow on the outside of the RPV was not effective because of flow anomalies.

- Insulating the RPV inner wall was effective in reducing RPV temperature to levels permitting the use of SA508/533 material during normal operation but the insulation caused excessive fuel temperatures during conduction cooldown events.

The preferred approach was the VCS flow through the annulus between the core barrel and the RPV (see Option 1 in Figure 4). The riser configuration through the permanent sider reflector (PSR) and the VCS flow are illustrated in Figure 5. ${ }^{9}$

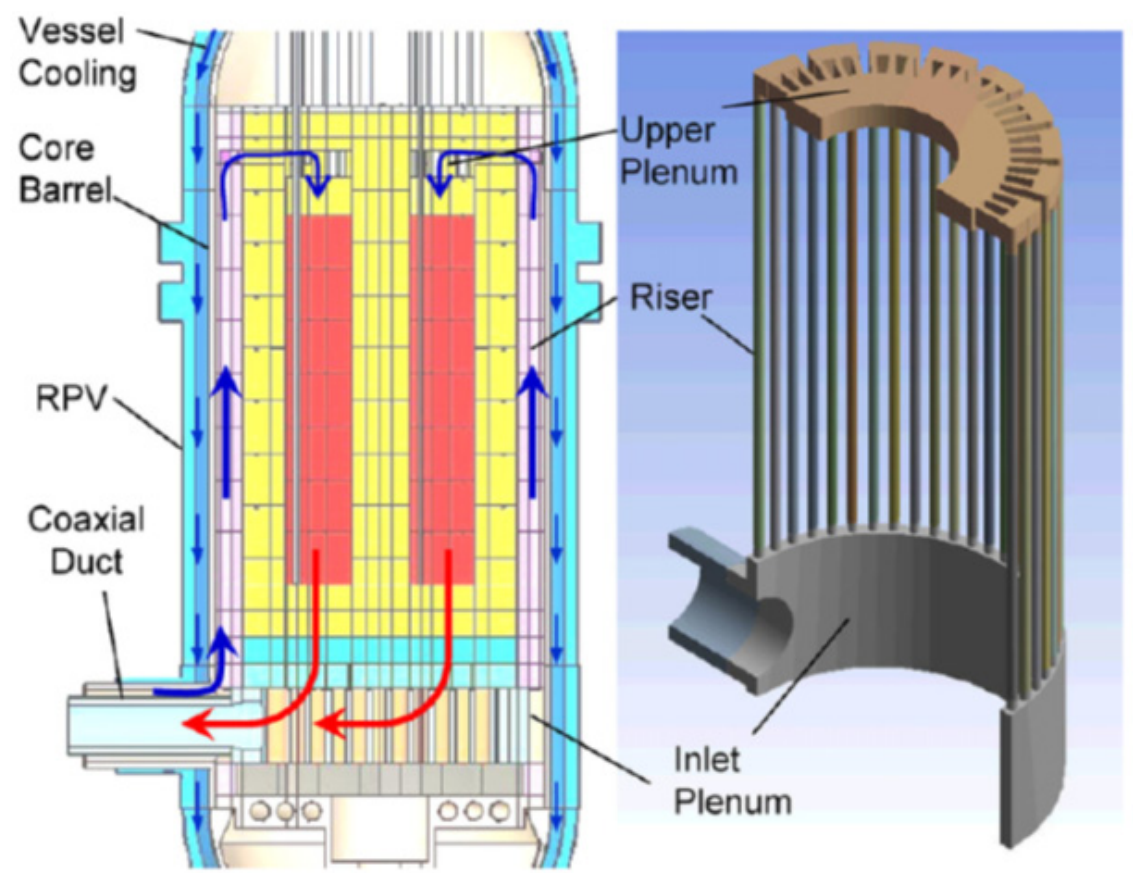

Figure 5. Configuration of the cooled-vessel design concept.

KAERI also evaluated the effect of moving the riser configuration closer to the core on RPV temperature for varying VCS flowrates. ${ }^{8}$ The following summarizes the results of those evaluations:

The effects of not only the cooling flow rate but also the riser location were investigated. Figs. 16 [shown below] and 17 [not shown] show the maximum temperatures of the RPV and the heat losses to the RCCS according to a change of the cooling flow rate and the riser location. The result for the case without a vessel cooling flow indicates the effect of changing the inlet flow configuration in the proposed cooled vessel concept. The maximum vessel temperature for the case with the original GT-MHR design was estimated to be about $577^{\circ} \mathrm{C}$ by the GAMMA code. ${ }^{\mathrm{g}}$ By changing the coolant flow path direction into the graphite structure, that is, by precluding a direct contact of the coolant with the vessel

g This is a high temperature for the original GTMHR, which had an RIT of $490^{\circ} \mathrm{C}$ and ROT of $850^{\circ} \mathrm{C}$. KAERI increased these temperatures to 590 and $950^{\circ} \mathrm{C}$ respectively for a VHTR design using the same core geometry as the GTMHR. These must be the reactor inlet and outlet temperatures used for this analysis. 
wall, the RPV temperatures are reduced by $100-120^{\circ} \mathrm{C}$ and the consequent heat losses are also reduced. However, this reduction is not enough to maintain the temperature below the limit of SA-508/533 steel which is $371^{\circ} \mathrm{C}$ (ASME, 2001). When introducing a small amount of a vessel cooling flow, $3.2 \mathrm{~kg} / \mathrm{s}$, the temperature is reduced by $100^{\circ} \mathrm{C}$. To ensure a temperature below $371^{\circ} \mathrm{C}$, more than $4 \mathrm{~kg} / \mathrm{s}$ of a vessel cooling flow is required. Moving the riser location closer to the core also reduces the resultant RPV temperature and heat losses.

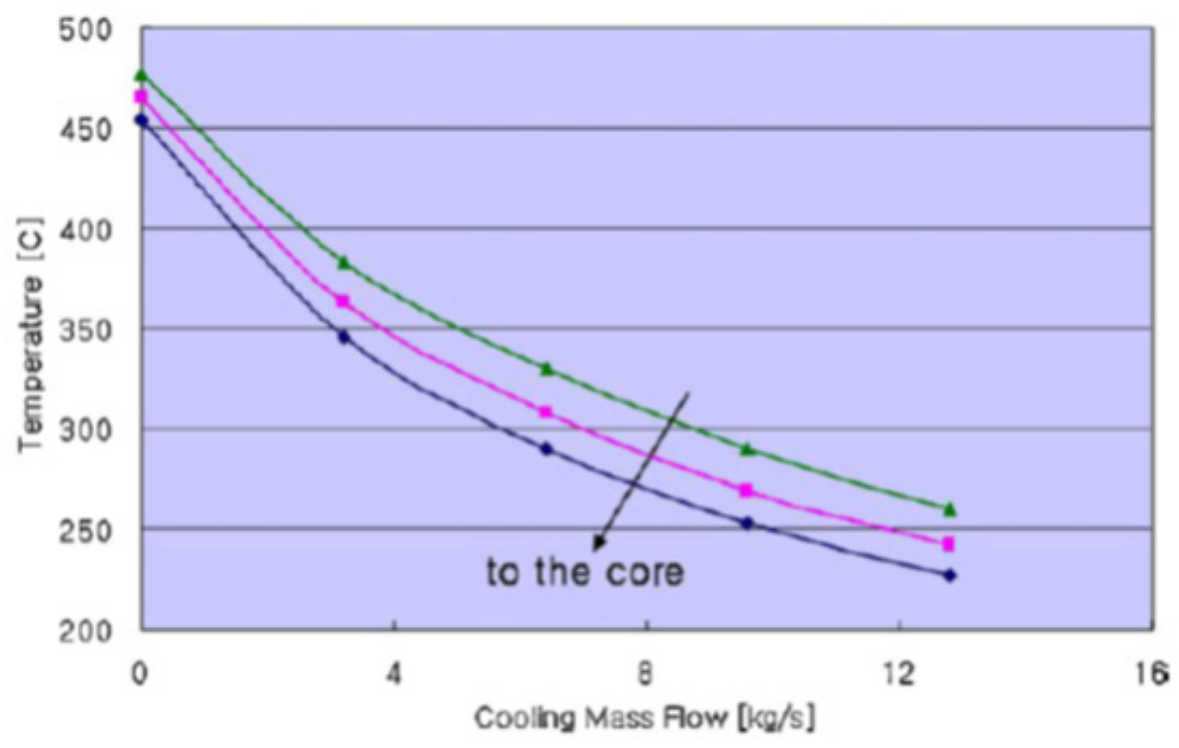

Fig. 16 Maximum temperatures of the RPV according to a change of the cooling mass flow and riser location. (from Reference 8)

The KAERI analyses were performed using a thermal-hydraulics code GAMMA+ and a computational fluid dynamics code CFX. Similar analyses were performed by Idaho National Laboratory (INL) for the General Atomics prismatic design in 2008 and 2012 using RELAP5-3D. These analyses were performed initially for a VHTR based on the General Atomics GTMHR design but with ROTs of 900 and $950^{\circ} \mathrm{C}$ versus the $850^{\circ} \mathrm{C}$ of the original ${ }^{10}$ design. Later analyses were performed for an ROT of $750^{\circ} \mathrm{C}$. The inlet flow configuration used for these analyses was a variation from that analyzed by KAERI in which the flow was directed through holes in the permanent side reflector rather than riser tubes. ${ }^{11}$ This configuration did not include a VCS. Table 3 summarizes the results of those analyses.

Table 3. Results of INL Analyses of RPV Temperature versus Reactor Inlet and Outlet Temperatures.

\begin{tabular}{lrrr}
\hline \multicolumn{1}{c}{ Parameter } & $\mathrm{T}_{\text {out }}=750{ }^{\circ} \mathrm{C}$ & $\mathrm{T}_{\text {out }}=900{ }^{\circ} \mathrm{C}$ & $\mathrm{T}_{\text {out }}=950^{\circ} \mathrm{C}$ \\
\hline Power, $\mathrm{MW}$ & 600 & 600 & 600 \\
Pressure, $\mathrm{MPa}$ & 7.00 & 7.00 & 7.00 \\
Differential pressure, $\mathrm{MPa}$ & 0.0519 & 0.0764 & 0.0802 \\
Inlet temperature, ${ }^{\circ} \mathrm{C}$ & 350 & 540 & 590 \\
Outlet temperature, ${ }^{\circ} \mathrm{C}$ & 750 & 900 & 950 \\
Flow rate, $\mathrm{kg} / \mathrm{s}$ & 292.7 & 325.0 & 325.1 \\
Core bypass, $\%$ & 10.01 & 9.59 & 9.53 \\
Maximum vessel temperature (inner wall), ${ }^{\circ} \mathrm{C}$ & 271 & 410 & 447 \\
Maximum vessel temperature (midwall), ${ }^{\circ} \mathrm{C}$ & 260 & 388 & 421 \\
Maximum fuel temperature, ${ }^{\circ} \mathrm{C}$ & 929 & 1064 & 1112 \\
RCCS power, $\mathrm{MW}$ & 0.86 & 1.83 & 2.13 \\
\hline
\end{tabular}


These results indicate that the move of the inlet flow to the permanent side reflector would result in RPV temperatures during normal operations that would permit use of SA508/533 material for ROTs in the range of 725 to $850^{\circ} \mathrm{C}$ without requiring any vessel cooling. Other materials or a VCS would be required for RIT higher than $850^{\circ} \mathrm{C}$.

These results and those of KAERI analyses indicate that moving the inlet flow inside the core barrel would permit use of SA 508/533 material for the RPV for the full range of ROT recommended by the NGNP Project $\left(725\right.$ to $\left.850^{\circ} \mathrm{C}\right)$. However, in analyses performed for the NGNP Project in 2008, AREVA raised several concerns with this approach ${ }^{12}$ :

Relocation of the core inlet flow path is not considered to be very feasible. It might be possible to implement it successfully, if significant compromises are made in other reactor design areas and overall plant operating conditions. However, it introduces or exaggerates several other design concerns which will be difficult to assess.

As discussed in the preceding subsections, major concerns include:

- Reduced core heat capacity (higher conduction cooldown temperatures)

- Altered reflector effective conductivity (higher core and/or vessel conduction cooldown temperatures depending on the specific event)

- Higher bypass flows (higher operating fuel temperatures)

- Higher vessel fast fluence during normal operation

- Reduced control rod worths

Proponents of this strategy have analyzed some of these considerations, but not all of them. A significant amount of core redesign and assessment would likely be necessary. It also appears to be costly option to implement. The number of permanent side reflectors (PSRs) that need to be bored out is significant. There are over 1000 PSR blocks that rest against the inner core barrel in a ring that is 12 PSR blocks high. GA proposed to have 72 inlet flow channels drilled in the PSRs. This equates to having to special machine 864 PSR blocks. In addition, design optimization to try to control bypass flows could be complex.

AREVA also evaluated other alternative configurations and materials for use in the event inlet temperatures exceed the Level A Service Limits of SA508/533, including insulation systems, thermal shields, and VCSs similar to those discussed previously. The AREVA study reached the following conclusions:

- $\quad$ The current RPV design can be considered acceptable using SA-508/SA-533 without design modifications up to a power level of $600 \mathrm{MW}(t)$ and a core inlet temperature of $400^{\circ} \mathrm{C}$.

- $\quad$ The implementation of a thermal insulation at the outer surface of the core barrel seems difficult to optimize and results in an unacceptable temperature for the core barrel.

- The alternative with a thermal shield provides promising results, even though further refinement would still be required.

- The implementation of active cooling for the RPV could be achieved with a limited impact in terms of overall plant efficiency. Such a cooling system 
would have no effect on temperatures reached during DCC situations, but vessel temperatures would be acceptable.

For the IHX vessel:

- The implementation of an active cooling of the IHX vessels would have a large impact on the efficiency.

- The option based on insulation on both inside and outside the IHX vessel would be preferable.

Thus, for systems with operating temperatures of $400^{\circ} \mathrm{C}$ (core inlet) and $800^{\circ} \mathrm{C}$ (core outlet), an SA-508/SA-533 vessel is a clear option.

For higher temperature operation, feasible alternatives appear to be available to allow the use of an SA-508/SA-533 vessel. However, whether these options are preferable to a vessel made of a higher temperature alloy remains to be determined. This question depends foremost on the availability of such a vessel. If a high temperature vessel such as modified $9 \mathrm{Cr}-1 \mathrm{Mo}$ [referred to as $9 \mathrm{Cr}-1 \mathrm{Mo}-$ $\mathrm{V}$ elsewhere in this report] is available, that would be a simpler option which would avoid the added complexity of the alternatives explored in this section. On the other hand, if such a vessel is not available, then these solutions may represent the only option.

INL evaluations of the use of the $9 \mathrm{Cr}-1 \mathrm{Mo}-\mathrm{V}$ material conclude that availability and fabricability of the material may be problematic for the RPV application. Calculations and tests also indicate that it may not be possible to achieve the needed microstructure in the deeper sections of the thicker forgings during casting, forging, and heat treating. INL is not currently pursuing qualification of this material.

With respect to the other vessels in the HTGR vessel system, insulation on the inner walls would be used to reduce the vessel wall temperatures in the cross vessel and in the heat transport system vessel for RITs that exceed the SA508/533 Level A Service Limits. Insulation may also be placed in the lower plenum of the RPV, if needed. The temperatures in these areas are not affected by conduction cooldown events. This insulation would typically be encapsulated solid material that would not present a hazard of coming loose and clogging flow passages during transient events.

In summary, SA508/533 RPV material is acceptable for normal operating conditions as follows:

- $\quad$ RITs $\leq 370^{\circ} \mathrm{C}$ are subject to meeting the current Code limit on negligible creep. Based on prior design data for prismatic cores, this would correspond to a maximum ROT of $\sim 770^{\circ} \mathrm{C}$. The recent recommendations by General Atomics ${ }^{13}$ and AREVA $^{14}$ for the initial deployment of the HTGR technology employ ROTs below this value, providing confidence that SA508/533 material can be used for the RPVs in these designs.

- ROTs $>770^{\circ} \mathrm{C}$ but $\leq 850^{\circ} \mathrm{C}$, obtained by redirecting the reactor inlet flow inside the core barrel either through riser tubes or holes in the permanent side reflector, are subject to meeting the criterion on negligible creep. A maximum RIT of $450^{\circ} \mathrm{C}$ and a configuration similar to the General Atomics GTMHR has been assumed.

- ROTs $>850^{\circ} \mathrm{C}$ but $\leq 950^{\circ} \mathrm{C}$, obtained by redirecting the reactor inlet flow inside the core barrel either through riser tubes or holes in the PSR and adding a VCS flow of low temperature helium through the annulus between the core barrel and the RPV, are subject to meeting the negligible creep criterion.

- Alternatives that need further investigation for RITs $>370^{\circ} \mathrm{C}$ is the addition of insulation to the inner wall of the RPV or using 9Cr-1Mo-V material for the vessel. 
- For all RITs $>370^{\circ} \mathrm{C}$, adding solid insulation to the inner walls of the cross vessel and heat transport system vessel will be required.

\subsection{Temperatures During Conduction Cooldown Events}

Scoping analyses performed by General Atomics in early 1992 investigated the impact of increasing power in the MHTGR design on passive heat removal. ${ }^{15}$ The reference rating for the MHTGR was 350 MW(t) at that time. These analyses evaluated peak fuel temperatures and peak reactor vessel temperatures during pressurized and DCC events for several plant configurations and core ratings. All analyses were performed for an ROT of $704^{\circ} \mathrm{C}$ and an RIT of $288^{\circ} \mathrm{C}$. The reactor vessel material was SA 508/533. Table 4 summarizes the results of those analyses ${ }^{\mathrm{h}}$ :

Table 4. Results of General Atomics 1992 MHTGR analyses.

\begin{tabular}{lccccc}
\hline \multicolumn{1}{c}{ Item } & Case A & Case B & Case C & Case D & Case E \\
\hline Rating, MW(t) & 450 & 410 & 450 & 450 & 500 \\
Fuel columns & 84 & 72 & 90 & 90 & 90 \\
Core layers & 10 & 10 & 10 & 9 & 10 \\
Power density, w/cc & 6 & 6.3 & 5.6 & 6.2 & 6.2 \\
Vessel ID, ft & 23.7 & 21.5 & 23.7 & 23.7 & 23.7 \\
Pressure, psia & 1025 & 1025 & 1025 & 1025 & 1025 \\
RIT, ${ }^{\circ} \mathrm{F}$ & 550 & 550 & 550 & 550 & 550 \\
RIT, ${ }^{\circ} \mathrm{C}$ & 288 & 288 & 288 & 288 & 288 \\
ROT, ${ }^{\circ} \mathrm{F}$ & 1300 & 1300 & 1300 & 1300 & 1300 \\
ROT, ${ }^{\circ} \mathrm{C}$ & 704 & 704 & 704 & 704 & 704 \\
Peak Temps for Pressurized Conduction & Cooldown (PCC) & Event & & \\
Fuel, ${ }^{\circ} \mathrm{C}$ & 592 & 603 & 618 & 640 & 622 \\
Vessel Side Wall, ${ }^{\circ} \mathrm{F}$ & 760 & 739 & 760 & 761 & 790 \\
Vessel Side Wall, ${ }^{\circ} \mathrm{C}$ & 404 & 393 & 404 & 405 & 421 \\
Upper Plenum Shroud, $^{\circ} \mathrm{F}$ & 1354 & 1420 & 1358 & 1383 & 1420 \\
Core Barrel, ${ }^{\circ} \mathrm{F}$ & 1325 & 1373 & 1330 & 1348 & 1390 \\
Core Barrel, ${ }^{\circ} \mathrm{C}$ & 718 & 745 & 721 & 731 & 754 \\
Operating control rod, ${ }^{\circ} \mathrm{F}$ & 1478 & 1520 & 1496 & 1532 & 1578 \\
Peak Temps for Depressurized Conduction Cooldown $($ DCC) Event & & \\
Average Fuel, ${ }^{\circ} \mathrm{C}$ & 1240 & 1350 & 1230 & 1300 & 1325 \\
Peak Fuel, ${ }^{\circ} \mathrm{C}$ & 1550 & $<1630$ & 1540 & $<1620$ & $<1620$ \\
Operating control rod, ${ }^{\circ} \mathrm{F}$ & $2050-2150$ & $>2285$ & $2300-2400$ & $2190-2290$ & $2210-2310$ \\
Vessel Side Wall, ${ }^{\circ} \mathrm{F}$ & 735 & 870 & 740 & 795 & 845 \\
Vessel Side Wall, ${ }^{\circ} \mathrm{C}$ & 391 & 466 & 393 & 424 & 452 \\
\hline
\end{tabular}

Case B increases the referenced $350 \mathrm{MW}(\mathrm{t})$ rating of the MHTGR core to $410 \mathrm{MW}(\mathrm{t})$ in the same reactor vessel diameter $(21.5 \mathrm{ft})$. The report states that this is the highest core rating achievable in this size

$\mathrm{h} \quad$ These analyses were performed early in the design process. Final design calculations made later show higher peak RPV temperatures for the reference MHTGR design at $350 \mathrm{MW}(\mathrm{t})$ that exceed the Level B Service Limits $\left(800^{\circ} \mathrm{F} / 425^{\circ} \mathrm{C}\right)$ for the DCC event. These results are summarized later in this report. 
reactor vessel, meeting the peak fuel temperature limits during limiting incidents. The report also states that Cases D and $\mathrm{E}$ are also at these limits.

\subsubsection{Peak RPV Temperatures Reached in DCC \& PCC Events}

Examination of these data shows that the peak RPV temperatures (referred to as Vessel Side Wall in Table $4^{i}$ ) reached during both conduction cooldown events exceed the Level A Service Design Limit temperature for SA508/533 material $\left(700^{\circ} \mathrm{F} / 370^{\circ} \mathrm{C}\right)$. The Level B Service Limit temperature $\left(800^{\circ} \mathrm{F} / 425^{\circ} \mathrm{C}\right)$ is exceeded for Cases B and $\mathrm{E}$ for the DCC event. There is no case in which the Level C and D Service Limit temperature is exceeded $\left(1000^{\circ} \mathrm{F} / 540^{\circ} \mathrm{C}\right)$. The peak RPV temperature reached during these events varies with configuration and the power density of the core.

Case B illustrates the impact of changing configuration and power density. The increase in core rating from 350 to $410 \mathrm{MW}(\mathrm{t})$ resulted from the addition of fuel columns from 66 to 72 and increasing the power density from 5.9 to $6.3 \mathrm{w} / \mathrm{cc}$ (watts/cubic centimeter) in the reference MHTGR vessel diameter of, $21.5 \mathrm{ft}$. The increase in the number of fuel columns moves the fuel closer to the RPV, reducing the heat capacity and resistance of the conduction path from the fuel to the RPV. The increase in rating increases the stored energy in the fuel elements. These combine to result in the highest peak RPV temperature reached in all cases evaluated.

Examining all cases using the same reactor vessel diameter $(23.7 \mathrm{ft})$ shows that the peak temperature appears to increase with core rating, (the peak temperatures reached for Case $\mathrm{E}$ at $500 \mathrm{MW}(\mathrm{t})$ are higher than for Cases A, C, and D at $450 \mathrm{MW}(\mathrm{t})$ ). However, the data also show that Case D has higher peak temperatures than Cases $\mathrm{A}$ and $\mathrm{C}$, even though they have the same core rating and vessel diameter. It is noted that Case $\mathrm{C}$ has more fuel columns than Case A (90 vs. 84) but the same number as Case D. Since Cases $\mathrm{A}$ and $\mathrm{C}$ have similar peak temperatures for all events, the difference in the number of fuel columns between Cases $\mathrm{A}$ and $\mathrm{C}$ and $\mathrm{A}$ and $\mathrm{D}$ appear to not be a significant effect. However, what distinguishes Case D from A and C is the number of fuel layers; nine for Case D vs. 10 for Cases A and C. This required increasing the power density in the fuel elements in Case D from $6.0 \mathrm{w} / \mathrm{cc}$ in Case A and $5.6 \mathrm{w} / \mathrm{cc}$ in Case $\mathrm{C}$ to $6.2 \mathrm{w} / \mathrm{cc}$. This is the same power density for Case E, but Case E has the full 10 fuel layers to achieve the higher core rating.

What this data shows is that the peak RPV temperature reached during the conduction cooldown events is a function of the fuel element volume, (e.g., number of fuel columns times number of fuel layers) and the power density. The product of these is an indication of the rating of the core; however, for a given core rating these factors individually affect the peak RPV and fuel temperatures reached in conduction cooldown events. The following discussion shows that if the effect of core rating on peak temperatures reached during conduction cooldown events is to be investigated, the number of fuel element layers and columns must be the same.

Figures 6 and 7 plot the peak RPV temperature reached in the DCC event against core rating and core power density. The position of Case B on both figures illustrates the effect of core configuration and power density on the peak RPV temperature reached during the DCC event (the high power density required to achieve the higher core rating in the smaller fuel element volume and smaller reactor vessel diameter produces the highest temperature response).

i These temperatures are assumed to be the peak average wall temperature reached during these events. 


\section{Peak RPV Temperature During a DCC Event as a Function of}

Core Rating

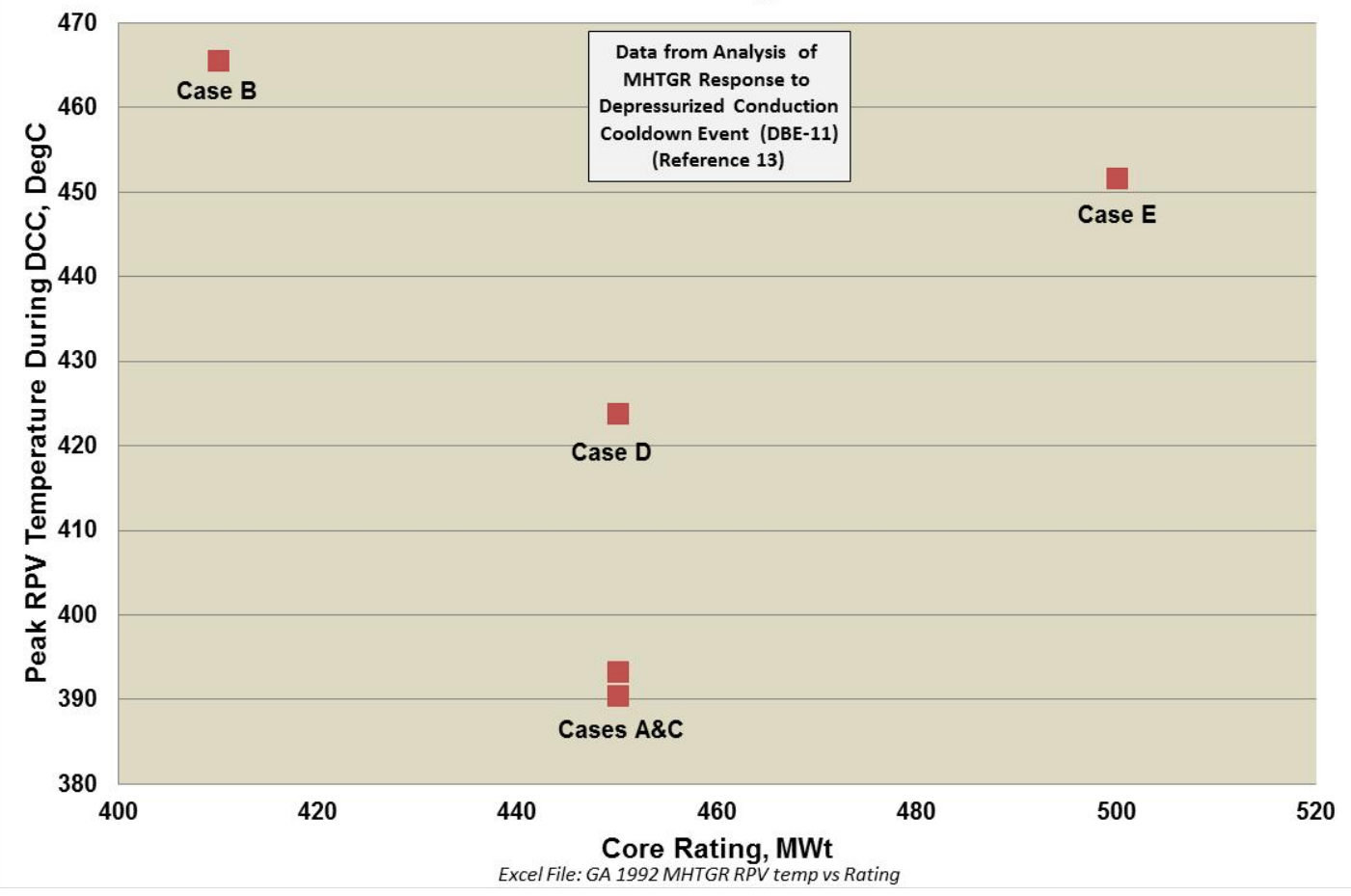

Figure 6. Peak RPV Temperature During a DCC Event as a Function of Core Rating.

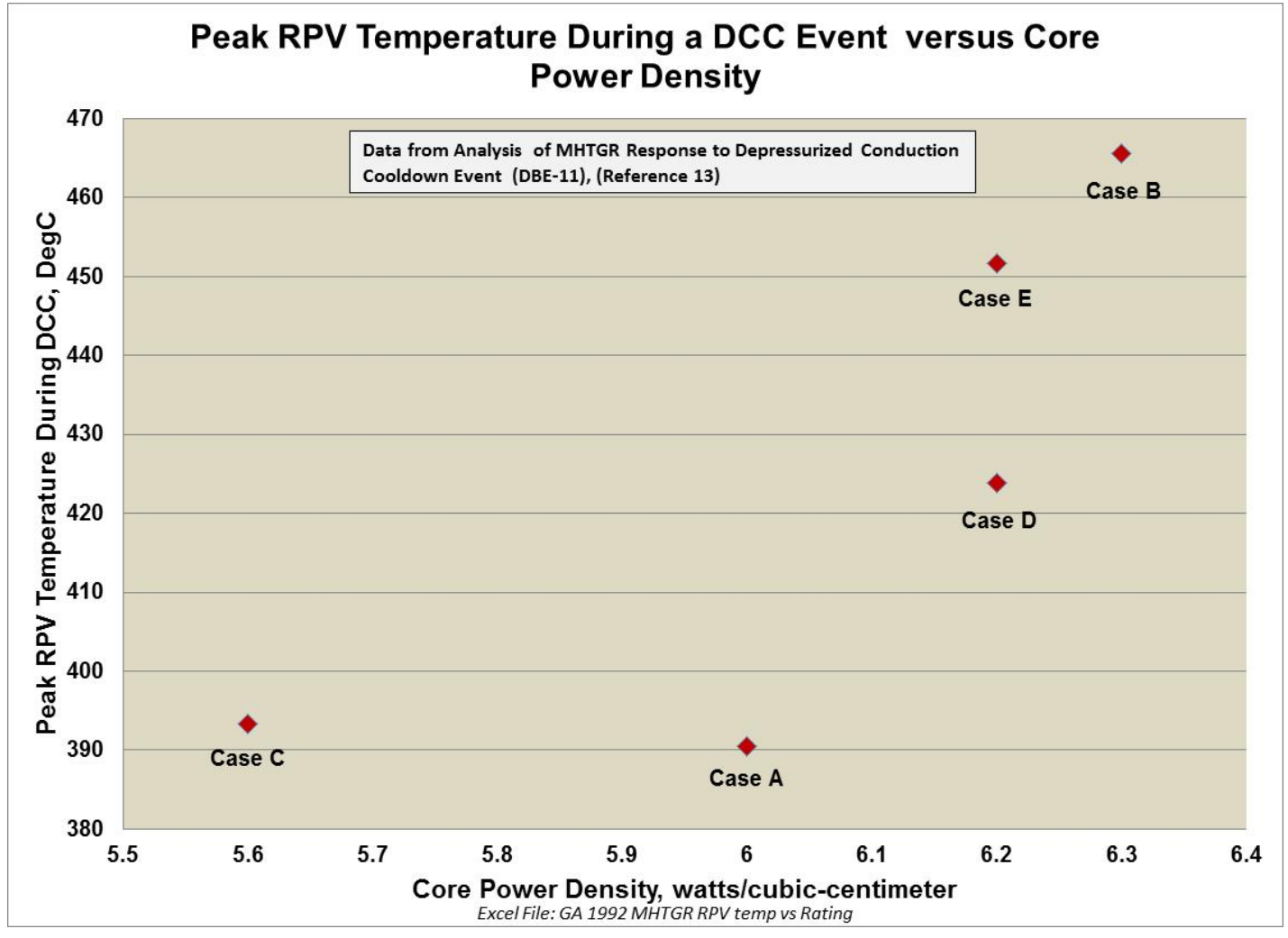

Figure 7. Peak RPV Temperature During a DCC Event as a Core Power Density. 
The similar responses of Cases $\mathrm{A}$ and $\mathrm{C}$ to this event (essentially the same peak temperatures are reached) show an offsetting effect of changing fuel element volume by changing the number of fuel columns (Case A has a fewer number of fuel columns) and power density, (Case A has a higher power density) for the same core rating $(450 \mathrm{MW}(\mathrm{t}))$.

Comparing Cases C and D shows a significant increase in peak RPV temperature reached in this event when the fuel volume is reduced by reducing the number of layers while holding the number of fuel columns constant (each case has 90 fuel columns but Case D has 9 layers whereas Case $\mathrm{C}$ has 10 layers) and the power density is increased (Case D power density is $0.6 \mathrm{w} / \mathrm{cc}$ higher than Case C). The significant increase in peak RPV temperature (from 393 to $424^{\circ} \mathrm{C}$ ) is because of the increased power density and the smaller area is because of the reduced height of the fueled volume for heat transport through the RPV to the reactor cavity cooling system (RCCS).

Cases $\mathrm{C}$ and $\mathrm{E}$ illustrate that the peak temperature reached during this event when the core configuration is constant is a strong function of fuel element power density; translated into core rating as the product of fuel element power density and volume.

The following conclusions were drawn from this exercise:

1. There are many design and performance characteristics that affect the peak temperature that the RPV will experience during conduction cooldown events. These include core configuration (e.g., number of fuel columns, number of fuel layers, diameter of the core and RPV) and fuel element power density.

2. When the core configuration is constant, the peak temperatures reached in conduction cooldown events will be a direct function of the core rating.

These analyses were performed for the same ROT and RIT. Figure 8 shows that, for the same core rating, the effect of varying ROT and RIT on the peak RPV temperature reached during a DCC is relatively small $\left(\sim 30^{\circ} \mathrm{C}\right)$. These analyses were performed for the GTMHR Plutonium Burner ${ }^{17}$ with a core rating of $600 \mathrm{MW}(\mathrm{t})$. This effect was also confirmed in the INL analyses summarized in References 10 and 18 as shown in Table 5. Although these analyses were performed for only the DCC, it is judged that the same results would be obtained for the PCC event. The conclusion of these analyses is that the reactor operating temperatures do not have a large influence on the peak RPV temperature reached during conduction cooldown events.

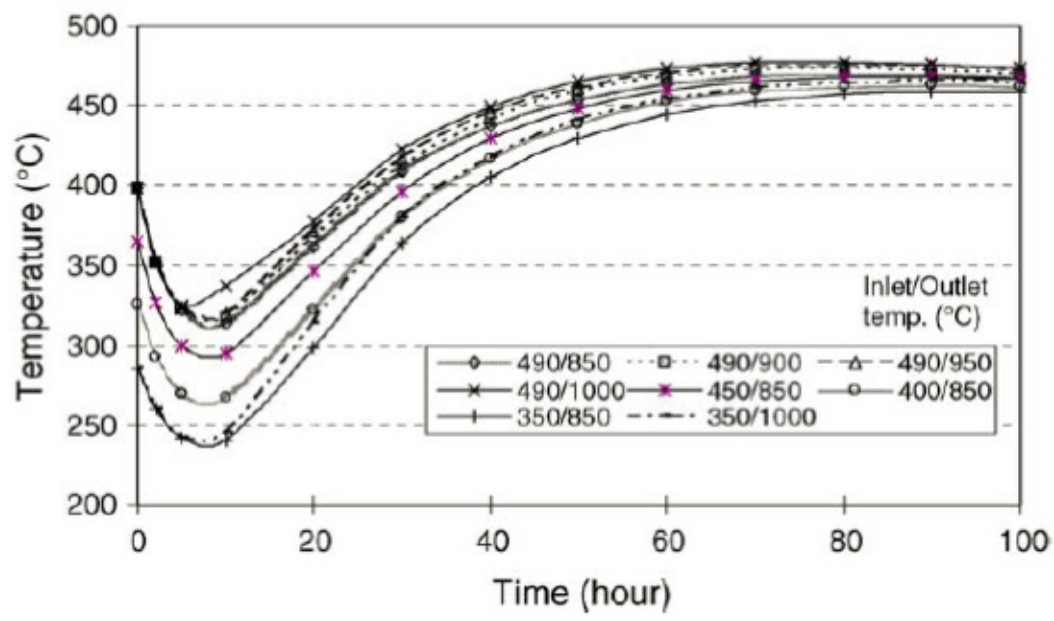

Figure 8. Influence of inlet/outlet temperature on maximum RPV temperature during a DCC (Figure 21 from Reference 16). 
Table 5. RPV Peak temperatures during the DCC event versus ROT. ${ }^{18}$

\begin{tabular}{lccc}
\hline \multicolumn{1}{c}{ Parameter } & $\mathrm{T}_{\text {out }}=750^{\circ} \mathrm{C}$ & $\mathrm{T}_{\text {out }}=900^{\circ} \mathrm{C}$ & $\mathrm{T}_{\text {out }}=950^{\circ} \mathrm{C}$ \\
\hline Maximum vessel temperature (inner wall), ${ }^{\circ} \mathrm{C}$ & 527 & 553 & 562 \\
Maximum vessel temperature (midwall), ${ }^{\circ} \mathrm{C}$ & 487 & 510 & 517 \\
Maximum fuel temperature, ${ }^{\circ} \mathrm{C}$ & 1423 & 1501 & 1526 \\
\hline
\end{tabular}

Although not shown explicitly in the preceding data and figures, the analyses reviewed in the course of this investigation covered different reactor inlet flow configurations. The MHTGR analyses were performed for a flow path in channels located within the annulus between the core barrel and the RPV inner wall. The KAERI analyses incorporated either a set of riser tubes or holes in the permanent side reflector inside the core barrel to transport the inlet flow from the cross-vessel to the upper plenum, which included vessel cooling in some cases. The inlet helium in the INL analyses flowed through holes in the permanent side reflectors inside the core barrel. The results of all of these analyses appear to show that the effect of these variations in reactor inlet configuration on peak temperatures reached during the conduction cooldown events is small compared with the other factors discussed in the preceding. This conclusion is similar to that reached in the evaluations summarized above. This conclusion will be confirmed during the design process.

\subsubsection{Time at Temperature During DCC and PCC Events}

As noted in the preceding, the peak RPV mid-wall temperatures reached during conduction cooldown events, whether pressurized or depressurized, exceed the ASME Code Level A Service Limit temperature of $700^{\circ} \mathrm{F} / 370^{\circ} \mathrm{C}$ for SA $508 / 533$ material. Since these events assume a loss of all forced cooling in the core (failure of the helium circulator and the shutdown cooling system), as in the case of the depressurized condition a breach of the helium pressure boundary, they are considered infrequent events that would be covered under Level B and C Service Limits. For SA508/533 material, the Code specifies for these limits that the time at temperatures in excess of $700^{\circ} \mathrm{F} / 370^{\circ} \mathrm{C}$ shall not exceed 3,000 hours and above $800^{\circ} \mathrm{F} / 425^{\circ} \mathrm{C}$ shall not exceed 1,000 hours. Three excursions of temperature that exceed $800^{\circ} \mathrm{F} / 425^{\circ} \mathrm{C}$ are allowed over the life of the vessel. There is also a maximum allowed temperature of $1000^{\circ} \mathrm{F} / 540^{\circ} \mathrm{C}$. This maximum temperature limit is not approached in all cases discussed previously.

Figure 9 shows the time history of the RPV mid-wall temperature during the DCC event for the General Atomics MHTGR design (Design Basis Event 11). ${ }^{19}$ This is a $350 \mathrm{MW}(\mathrm{t})$ reactor with ROT/RIT of $687 / 259^{\circ} \mathrm{C}$. Also shown on this figure are the Level A, B, C and D Service Limit temperatures. This transient was calculated for an instrument line break in the helium primary system with operator action to depressurize the system to near atmospheric pressure in the first several hours of the transient. As was the case for the analyses discussed previously, the Level A $\left(700^{\circ} \mathrm{F} / 370^{\circ} \mathrm{C}\right)$ and Level B $\left(800^{\circ} \mathrm{F} / 425^{\circ} \mathrm{C}\right)$ Service Limit temperatures are exceeded by the peak temperature reached in the event $\left(\sim 820^{\circ} \mathrm{F} / 438^{\circ} \mathrm{C}\right)$. The 115 hours for which the Level B Service Limit temperature is exceeded is well below the 1,000 hour Code Limit and the 346 hours for which the Level A Service Limit temperature is exceeded is well below the 3,000 hour Code limit. Because the Level B Service Limit temperature is exceeded, however, the RPV would not be available for further operation upon three of these occurrences. 


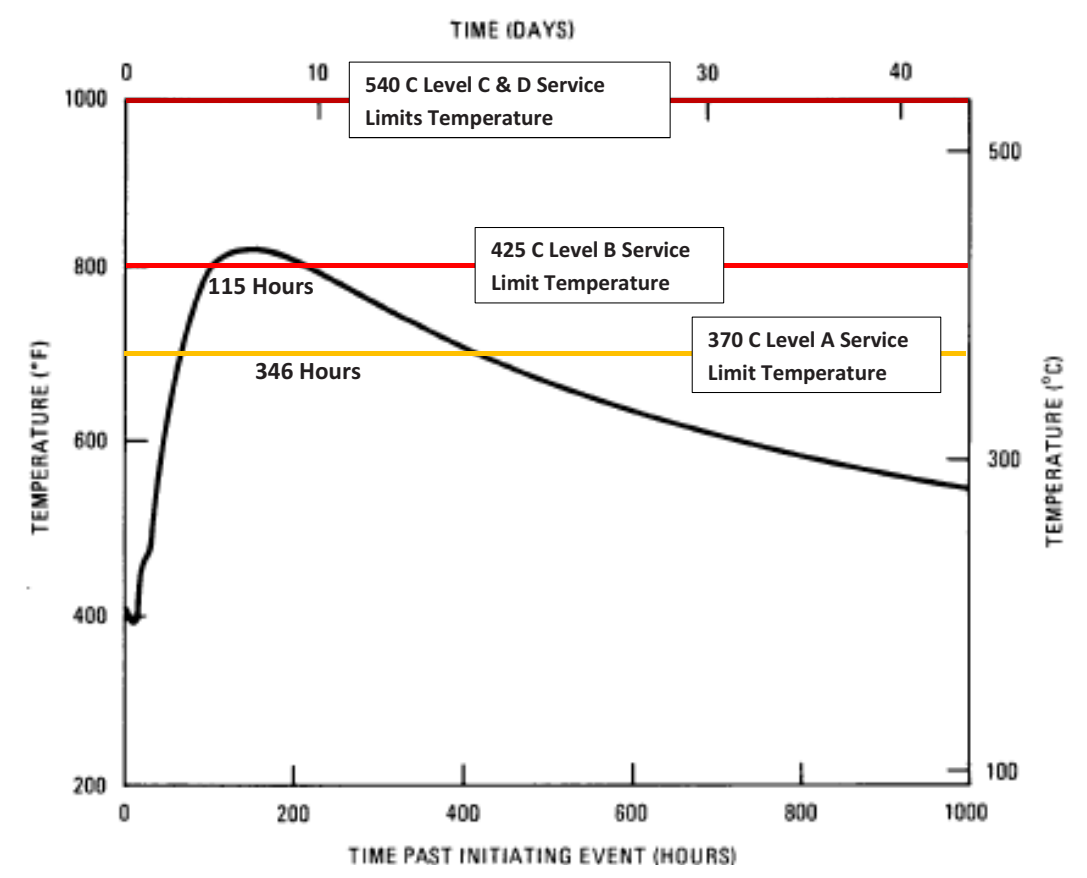

Figure 9. RPV Temperature Response During DCC, 350 MW(t) MHTGR.

Figures 10 and 11 show similar time histories of RPV midwall temperature during pressurized and DCC analyses for the $600 \mathrm{MW}(\mathrm{t})$ core with ROT/RIT of $950 / 490^{\circ} \mathrm{C}$ of Reference 8 . As cited previously, the reactor inlet flow in this core design passes through risers inside the core barrel with low temperature helium $\left(140^{\circ} \mathrm{C}\right)$ flowing through the core barrel to RPV annulus to maintain the vessel temperature within design limits. That is why the transients begin with an RPV temperature of $\sim 330^{\circ} \mathrm{C}$ even though the RIT is $490^{\circ} \mathrm{C}$. It is assumed in the analyses that once the conduction cooldown transients start, the cooling flow is stopped. The depressurized transient assumes that the loss of pressure in the core is rapid and that there is, therefore, no helium convective heat transfer between the core and the RPV.

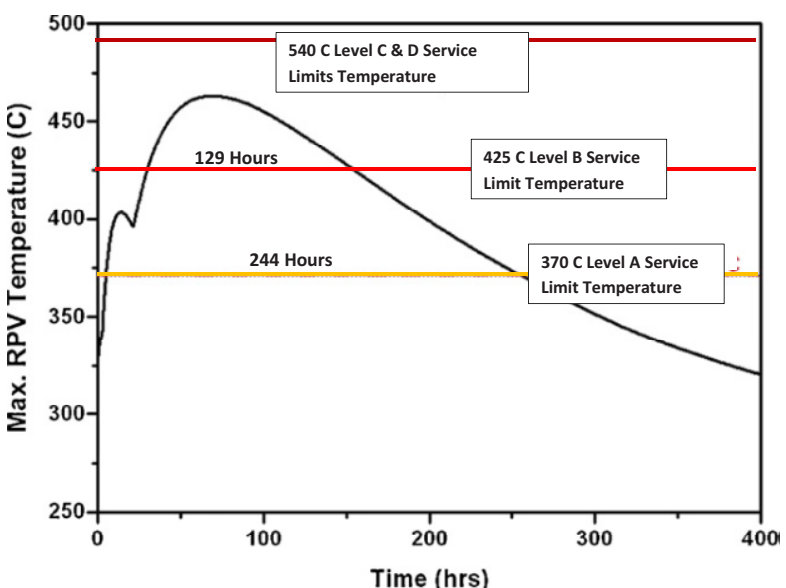

Figure 10. RPV temperature response to PCC event, $600 \mathrm{MW}(\mathrm{t}) \mathrm{GT}-\mathrm{MHR}$.

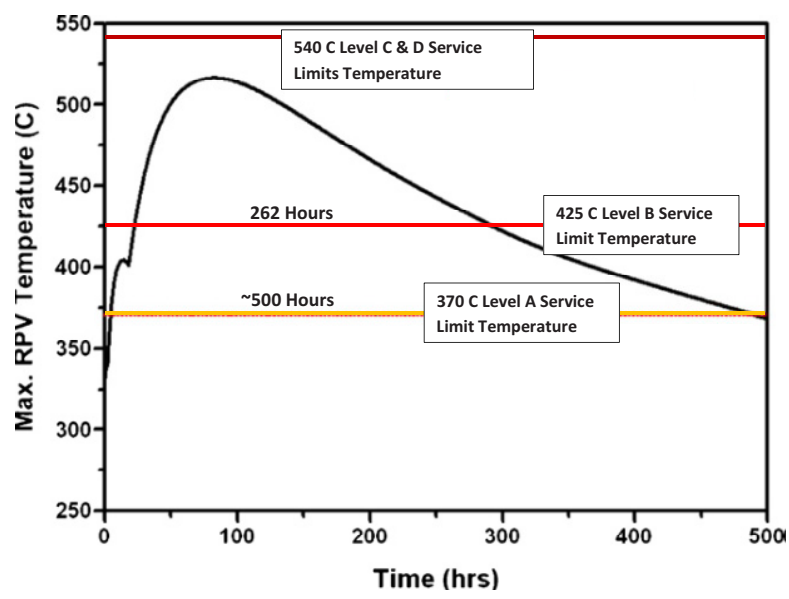

Figure 11. RPV temperature response to DCC event, $600 \mathrm{MW}(\mathrm{t}) \mathrm{GT}-\mathrm{MHR}$.

In both transients the peak temperatures do not reach the maximum temperature limit of $1000^{\circ} \mathrm{F} / 540^{\circ} \mathrm{C}$. In both cases, the times over which the Level A and Level B Service Limit temperatures are exceeded are well within the periods allowed by the Code. However, since the Code allows only three 
events exceeding the Level B Service Limit temperature $\left(800^{\circ} \mathrm{F} / 425^{\circ} \mathrm{C}\right)$, the RPV would not be permitted to continue operation upon any three combinations of these transients.

The much higher peak temperatures and the longer durations of these temperatures in the DCC event compared with the temperatures for the MHTGR (see Figure 9) reflects the higher rating of this core $(600 \mathrm{MW}(\mathrm{t}))$ versus that of the MHTGR (350 MW(t)).

The conclusions to be drawn from review of this data are:

1. For the designs of the plants reviewed herein with core ratings up to $600 \mathrm{MW}(\mathrm{t})$, the temperatures reached and the time periods in which these temperatures exceed Level A and B Service Limit temperatures for SA508/533 do not preclude the use of this material for the RPV. The trends in increasing peak RPV mid-wall temperatures with core rating indicate that this conclusion would apply for a core rating of $625 \mathrm{MW}(\mathrm{t})$. This will be confirmed during the design process.

2. The durations of the periods over which Service Design Limits are exceeded during conduction cooldown events increase with the thermal rating of the core. This is similar to the conclusion on the effect of core rating on peak temperatures reached during these transients.

3. Three of these transients for the higher core ratings would appear to not permit continued operation of the RPV because of current limits on the number of times the Level B Service Limits $\left(800^{\circ} \mathrm{F} / 425^{\circ} \mathrm{C}\right)$ can be exceeded. This was true for Cases B and E of General Atomics analyses (Table 4, $410 \mathrm{MW}(\mathrm{t})$ with high power density and $500 \mathrm{MW}(\mathrm{t}))$ and all $600 \mathrm{MW}(\mathrm{t})$ designs reviewed.

4. The analyses covered several different configurations of the reactor inlet flow path from the cross vessel to the upper plenum. Several of these included paths through the reflector inside the core barrel. The descriptions of the methods used in these analyses were not of sufficient detail to determine if the concerns raised by AREVA on the effects of these configurations on the temperature calculations during conduction cooldown events were addressed. Those concerns will need to be resolved in future design work. 


\section{REFERENCES}

1. AREVA, NGNP Risk Evaluation of Major Components, Document No. 12-9075581-000, April 2008

2. Idaho National Laboratory, NGNP 2011 Status and Path Forward, INL-EXT-11-23907, Appendix E, December 2011

3. ASME, ASME Boiler and Pressure Vessel Code, Section III, Rules for Construction of Nuclear Facility Components, Division 5, "High Temperature Reactors," American Society of Mechanical Engineers, 2011 First Issuance, November 1, 2011

4. ASME, ASME Boiler and Pressure Vessel Code, Section III, Rules for Construction of Nuclear Facility Components, Subsection NCA, "General Requirements for Division 1 and Division 2," American Society of Mechanical Engineers, 2010 Edition with 2011 Addenda

5. ASME, ASME Boiler and Pressure Vessel Code, Section III, Rules for Construction of Nuclear Facility Components, Division 1, Subsection NH, "Class 1 Components in Elevated Temperature Service," American Society of Mechanical Engineers, 2010 Edition with 2011 Addenda

6. General Atomics, Evaluation of Alternate HTGR Technology Applications, NGNP-R00017, Revision 0, General Atomics, December 2010, Appendix A

7. General Atomics, RPV and IHX Pressure Vessel Alternatives Study Report, 911118/0, April 2008

8. Min-Hwan Kim, Hong-Sik Lim, Won-Jae Lee, "A thermal-fluid assessment of a cooled-vessel concept for a VHTR," Korea Atomic Energy Research Institute, Nuclear Engineering and Design, 238 (2008), 3360-3369

9. Min-Hwan Kim, Nam-il Tak, Hong-Sik Lim, "Thermal-fluid assessment of the design options for reactor vessel cooling in a prismatic core VHTR," Korea Atomic Energy Research Institute, Technical Note, Science Direct, Annals of Nuclear Energy, 37 (2010), 1774-1782

10. H. D. Gougar, C. B. Davis, Reactor Pressure Vessel Temperature Analysis For Prismatic And Pebble-Bed VHTR Designs, Idaho National Laboratory, INL-EXT-06-11057, April 2006

11. Reza, S. M. M., E. A. Harvego, M. Richards, A. Shenoy, and K. L. Peddicord, 2006, "Design of Alternative Configuration of Coolant Inlet Flow for Modular High Temperature Helium Cooled Reactor," Proceedings of ICAPP '06, Reno, NV USA, June 4-8, Paper 6338

12. AREVA, NGNP with Hydrogen Production RPV and IHX Pressure Vessel Alternatives, 12-9076324001, April 2008

13. NGNP-R00016, Revision 1, Next Generation Nuclear Plant (NGNP) Prismatic HTGR Conceptual Design Project Conceptual Design Report - Steam Cycle Modular Helium Reactor (SC-MHR) Demonstration Plant, Prepared by General Atomics, U.S. Department of Energy/Office of Nuclear Energy, Cooperative Agreement DE-NE0000245, GA Project 30348, WBS 5900, Issued July 15, 2011

14. L. J. Lommers, F. Shahrokhi1, J. A. Mayer III, F. H. Southworth, "AREVA HTR Concept for NearTerm Deployment, ” AREVA, Proceedings of HTR 2010, Prague, Czech Republic, October 18-20, 2010, Paper 132 and presentation material used at the conference

15. T.D. Dunn, A.A. Schwartz, F.A. Silady, Impact of Increasing MHTGR Power on Passive Heat Removal, General Atomics, GA-A20998, July 1992

16. H. Haque, W. Feltes, G. Brinkmann, "Thermal response of a modular high temperature reactor during passive cooldown under pressurized and depressurized conditions," Framatome ANP GmbH, Nuclear Engineering and Design, 236 (2006), 475-484 
17. International Atomic Energy Agency, 2000, Heat Transport and Afterheat Removal for Gas Cooled Reactors Under Accident Conditions, GT-MHR Plutonium Burner, IAEA-TECDOC-1163, International Atomic Energy Agency, Vienna (Chapter 3.4)

18. E-mail, C.B. Davis (INL) to H.D. Gougar (INL), "RPV Temperatures," January 19, 2012 08:57AM, with attachment

19. General Atomics, HTGR Preliminary Safety Information Document for the Standard MHTGR, HTGR 86-024, Revision 13, Figure 15.12-7, September 1992 